\title{
ANÁLISE ECONÔMICA DAS DECISÕES DA ADMINISTRAÇÃO PÚBLICA
}

\section{ARTIGO ORIGINAL}

SETIM, Carla Regina Buschmann ${ }^{1}$

SETIM, Carla Regina Buschmann. Análise econômica das decisões da Administração Pública. Revista Científica Multidisciplinar Núcleo do Conhecimento. Ano 04, Ed. 09, Vol. 05, pp. 107-127. Setembro de 2019. ISSN: 2448-0959, Link de acesso: https://www.nucleodoconhecimento.com.br/administracao/analiseeconomica

\section{RESUMO}

A Constituição Federal de 1988 atribuiu à Administração Pública a efetiva concretização de direitos fundamentais, condicionando a função administrativa aos princípios da legalidade, impessoalidade, moralidade, publicidade e eficiência. A atividade administrativa tem como escopo $O$ atendimento aos cidadãos. $O$ uso ponderado dos recursos públicos constitui ponto nuclear para que a Administração exerça seu papel. Os atos administrativos consistem em normativos; ordinários; de negócio; enunciativos e punitivos. Cabe aos agentes públicos a análise dos requerimentos que the são apresentados. Denota-se, portanto, que uma cuidadosa análise dessas decisões pode ser determinante no controle dos gastos. Continuamente se vê o aumento exponencial de ações propostas ao Poder Judiciário, decorrentes de decisões que negam direitos aos cidadãos. A ciência econômica vem como forma auxiliar da Administração. A análise econômica das decisões pode fornecer substrato para que a Administração mude ou reconsidere seus

\footnotetext{
${ }^{1}$ Mestranda no programa de mestrado em Direitos Fundamentais e Democracia do Centro Universitário Autônomo do Brasil - UNIBRASIL/PR; especialização em Direito Civil e Processo Civil da Universidade Estadual de Londrina/PR; graduada em Educação Física e Direito pela Pontifícia Universidade Católica/PR.
} 
procedimentos, tornando-a mais eficiente. Exemplo disso consiste nas ações em face do Instituto Nacional do Seguro Social, vez que na grande maioria, poderiam ter sido resolvidas no âmbito administrativo. A problemática do presente artigo reside na conjunção da atividade administrativa e ciência econômica como forma de se evitar despesas orçamentárias desnecessárias, como os custos judiciais. As reflexões tiveram como apoio, textos; artigos e livros e indicam a necessidade de racionalização dos recursos públicos, em todos os níveis, para a efetiva concretização de direitos fundamentais.

Palavras-chave: finanças públicas, atos administrativos, economia.

\section{INTRODUÇÃO}

No presente artigo, reflete-se sobre o impacto nas finanças públicas das decisões da Administração Pública.

Consagrou-se no artigo $1^{\circ}$ da Constituição Federal o Estado Democrático de Direito, fundado na soberania popular, na cidadania, na dignidade da pessoa humano e no pluralismo.

À Administração Pública atribuiu-se a prestação de variados serviços públicos alçados à categoria de direitos fundamentais e, é por intermédio desses serviços que direitos fundamentais são concretizados. Tem-se hoje, que o papel desempenhado pela Administração Pública, estabelece e concretiza objetivamente políticas de Estado e públicas; portanto, seu papel é fundamental. Essa essencialidade reflete-se em outros setores importantes do Estado, dentre os quais, a racionalização das despesas orçamentárias.

A boa Administração Pública produz um desenvolvimento geral e igualitário do país e da vida dos cidadãos. O Estado Brasileiro possui uma máquina estatal de grande proporção, tendo em vista seu território e diferenças regionais. Portanto, não se quer simplesmente tecer críticas ao sistema vigente, mas, sobretudo, provocar reflexões que auxiliem na melhoria dos serviços e razoável uso dos recursos. A melhoria que 
aqui se propõe trata da análise e consequências econômicas que as decisões administrativas podem surtir. Não se trata de maximizar, termo eminentemente da ciência econômica, a economia, mas de torná-la uma aliada nas decisões diárias que a Administração Pública toma. A concretização de tais reflexões não constitui demanda descomplicada nem impossível.

\section{CONSTITUCIONALIZAÇÃO DA ADMINISTRAÇÃO PÚBLICA}

Vale frisar, que a Constituição Federal de 1988 inaugurou uma nova fase nos contextos social, político, legislativo e executivo. O Estado torna-se, subitamente, maior e mais abrangente, mas, sobretudo, garantidor de direitos.

A irradiação material e valorativa das normas constitucionais por todo o "sistema jurídico" é o que denomina Barroso de "efeito expansivo das normas constitucionais" (BARROSO, 2012, p.42).

Os valores, fins públicos, princípios e regras da Constituição conferem validade e sentido às normas infraconstitucionais; seja na relação dos Poderes com os particulares, seja na relação entre particulares, ou ainda, na relação entre administração e administrados.

A Constituição Federal de 1988 tratou da Administração Pública em seu Capítulo VII, contudo, observa-se em toda sua extensão a importância dos serviços públicos como meio efetivo de promoção dos preceitos fundamentais da República (art.3ํㅡ, CF/88).

A complexidade e eficaz interação da Administração Pública na satisfação de direitos fundamentais, consolidada na Carta Magna, vai muito além do que era concebido anteriormente à promulgação da Constituição.

A constitucionalização limita e conforma a elaboração das leis; na esfera administrativa, limita sua discricionariedade, impõe deveres, fornece fundamento para a consecução de atos diretos e imediatos, sem necessidade de lei; no âmbito judicial serve de parâmetro no controle de constitucionalidade e condiciona a interpretação judicial. 
Ensina Barroso que a

[...]Constituição passou a desfrutar já não apenas da supremacia formal que sempre teve, mas também de uma supremacia material, axiológica, potencializada pela abertura do sistema jurídico e pela normatividade de seus princípios[...]" passando a participar da "paisagem jurídica do país e no discurso dos operadores jurídicos.(BARROSO, 2012, p.42)

No que concerne ao Direito Administrativo, depreende-se que possui objetivo comum aos preceitos constitucionais, este versa estabelecer normas e procedimentos que garantam amplamente os direitos estabelecidos na Carta Magna.

Nesse contexto, o marco constitucional iniciou, também, nova forma de interpretação, o autor explica

Diretamente, quando uma pretensão se fundar em uma norma do próprio texto constitucional[...]Indiretamente, quando uma pretensão se fundar em uma norma infraconstitucional, por duas razões: antes de aplicar a norma, o intérprete deverá verificar se ela é compatível com a Constituição, porque, se não for, não deverá fazê-la incidir. Esta operação está sempre presente no raciocínio do operador do direito, ainda que não seja por ele explicitada; ao aplicar a norma, o intérprete deverá orientar seu sentido e alcance à realização dos fins constitucionais (BARROSO, 2012, p.43)

O espírito constitucional demonstra, portanto, a importância da Administração Pública na consecução dos princípios republicanos, destinando todo um capítulo ao seu aparato; e, esse novo olhar lançado sobre o aparato estatal e sua administração, impõe atuação positiva e negativa dos administradores.

Observa-se, assim, uma mudança nos paradigmas da Administração Pública, cujo interesse público, agora, parte do interesse da sociedade aliado aos valores de justiça, segurança e bem-estar social, constituindo este e o interesse primário. E o erário, passa a figurar como um interesse público secundário; em caso de colisão, o quadro deve ser analisado concretamente e sopesadas as circunstâncias.

Outra mudança ocorreu quanto à vinculação do administrador, que deve atentar aos preceitos constitucionais e à lei ordinária, nesta ordem. 
Muitos estudiosos alertam que as tensões entre os ideais constitucionais e o princípio democrático, vai além da preponderância da maioria, mas, em socorro, principalmente, das minorias.

Caminhando de 1988 até o tempo atual, temos a possibilidade de controle judicial do ato administrativo hoje, que vai além da sua formalidade, atinge o mérito da questão; não se subestimando, evidentemente, a discricionariedade do administrador.

O papel desempenhado pelo Poder Judiciário deve ser o de resguardar o ideal democrático e vivificar os preceitos constitucionais, honrando seus limites institucionais.

No entanto, o que se vem observando é a atuação cada vez mais abundante do Poder Judiciário, denominada hodiernamente de judicialização dos direitos constitucionais dos cidadãos, seja na área da saúde seja na previdência ou assistência social, ou ainda, no exercício de atividades empresariais; contemplando o que os agentes públicos objetam em razão, ocasionalmente, do despreparo, do desconhecimento da Constituição Federal e temor das consequências que pode vir a experimentar.

\section{DECISÕES ADMINISTRATIVAS}

As funções do Estado são universais, com objetivo único de resguardar o interesse público. A Constituição Federal de 1988

constitui marco no presente artigo. O Estado do Bem-Estar Social, cujos ideais foram retomados pela Constituição, tem o dever prestar, garantir e concretizar todos os direitos fundamentais.

O artigo 37 da Constituição Federal elegeu a legalidade, a impessoalidade, a moralidade, publicidade e eficiência, como os princípios norteadores da administração pública direta ou indireta da União, Estados, do Distrito Federal e dos Municípios, logo, os agentes ou administradores públicos estão constritos a eles. Qualquer decisão, ato ou disposição têm o dever de considerar os princípios norteadores da administração, 
os princípios constitucionais gerais e as leis; de modo igual, também as discricionárias.

De acordo com as lições de Meirelles

Em sentido lato, administrar é gerir interesses, segundo a lei, a moral e a finalidade dos bens entregues à guarda e conservação alheias. Se os bens e interesses geridos são individuais, realiza-se administração particular; se são da coletividade, realiza-se administração pública. Administração pública, portanto, é a gestão de bens e interesses qualificados da comunidade no âmbito federal, estadual ou municipal, segundo os preceitos do Direito e da Moral, visando ao bem comum. No Direito Público - do qual o Direito Administrativo é um dos ramos - a locução Administração Pública tanto designa pessoas e órgãos governamentais como a atividade administrativa em si mesma. Assim sendo, pode-se falar de administração pública aludindo-se aos instrumentos de governo como à gestão mesma dos interesses da coletividade (MEIRELLES, 2006, p.84)

Definida a atividade administrativa, compreende-se que seu encargo é público, abrigando, sustentando e acurando todos os serviços e interesses da coletividade.

Para tanto, os agentes e administradores são devidamente investidos em seus cargos ou funções, por intermédio de concurso público. São dotados de poderes para atos correspondentes à sua efetiva atuação no interesse da sociedade, que é o que condiciona respectiva atuação administrativa.

Previamente ao tema do artigo, que se relaciona intimamente com a ciência econômica, necessária breve síntese sobre os atos administrativos. As atividades administrativas ou dos agentes públicos são expressas por meio de: a) atos normativos - feitos gerais e intangíveis cujo objetivo é a correta aplicação da lei (decreto, regulamento, regimento, resolução, deliberação); b) atos ordinatórios - atos dirigidos estritamente à gerência da administração e seus agentes (instruções, circulares, avisos, portarias, ofícios, despachos administrativos); c) atos de negócios - disciplinam a atividade dos particulares de conformidade com a da Administração (licença, autorização, permissão, aprovação, visto, homologação, dispensa, renúncia); d) atos enunciativos - certificação ou atestado sobre fatos, sem vinculação 
ao seu conteúdo (atestado, certidão, parecer); e) atos punitivos - dispensa maiores explicações vez que autoexplicativo.

Por fim, quanto ao conteúdo que interessa ao artigo, pondera-se acerca da menor ou maior liberdade de ação dos atos administrativos vinculados e discricionários.

Vinculados são os atos praticados em obediência estrita à lei. Os atos discricionários podem ser praticados com certa liberdade em relação ao seu conteúdo, destino, em razão da oportunidade e modo de efetivação.

Sem embargo dos pedidos descabidos perpetrados junto aos órgãos do Poder Executivo e das ações temerárias propostas frente ao Poder Judiciário, o que vem se notando diuturnamente é o aumento exponencial das negativas administrativas, em todas as esferas públicas, ou a dificuldade imensa que os cidadãos encontram na efetivação dos seus direitos.

O relatório de auditoria sob ํo 009.253/2015-7, Acórdão 1787/2017 do Tribunal de Contas da União, que teve como objetivo a implementação de uma "fiscalização de orientação centralizada"; a identificação do perfil, da quantidade e do respectivo impacto "das ações judiciais na área da saúde"; a investigação do Ministério da Saúde para mitigar seus efeitos nos orçamentos e no acesso dos usuários à assistência à saúde"; dentre outras questões reflexas, demonstra de forma clara e objetiva - muito embora esteja propenso a especializar o Judiciário, o que não nos parece muito prodigioso, visto que o custo para o Estado vai continuar onerando os cofres públicos - que as decisões tomadas no âmbito administrativo, além de concretizarem os direitos constitucionais dos cidadãos e operacionalizarem as leis; devem, sobretudo, atentar para a análise econômica de suas decisões; principalmente, em razão da assombrosa recessão que passa o Brasil.

Referido estudo parte das indagações seguintes

a) Qual é o perfil das demandas judiciais na área da saúde pública? b) Qual é o impacto financeiro do cumprimento das demandas judiciais referentes à saúde pública no âmbito da União, do Distrito Federal, dos estados e dos municípios selecionados para análise? c) Que medidas 
estão sendo tomadas para aperfeiçoar a atuação do Poder Judiciário nos processos relativos ao direito sanitário/à saúde pública?

b) Que ações o Ministério da Saúde tem realizado para conhecer e mitigar os efeitos negativos da judicialização da saúde? e) Que medidas os órgãos locais têm adotado para lidar com a judicialização da saúde? (TCU ACÓRDÃO 1787/2017, p.4)

Das considerações abaixo, extrai-se a importância na racionalização, interligação, operacionalização e efetividade da administração, que, por conseguinte, redundam num aproveitamento excelente dos recursos ou da economia.

Diante da impossibilidade de ofertar toda e qualquer terapêutica para todos os usuários do SUS, é necessário alocar os recursos disponíveis de forma racional, considerando critérios de eficácia, segurança e custoefetividade. Essa racionalidade alocativa é levada em consideração na formulação e atualização dos protocolos clínicos e das relações do SUS. Todavia, a judicialização da saúde reorienta o fluxo do atendimento das necessidades de saúde, com base em informações e provas contidas em cada processo judicial isolado, inviabilizando uma racionalidade sistêmica no acesso a ações e serviços de saúde. Desse modo, é indispensável que o gestor tenha mecanismos eficazes de diagnóstico da situação atual, a fim de tomar decisões e adaptar estratégias com base em evidências. Dispor de informações completas sobre as demandas judiciais e de forma sistematizada possibilita ao gestor identificar falhas na gestão, desperdícios de recursos públicos, prescrições inadequadas e eventuais indícios de fraude. (TCU ACÓRDÃO 1787/2017, p.6)

O mencionado relatório, contudo, peca, quando resume o problema da judicialização das questões de saúde a tão somente um "fenômeno que ocorre na intersecção entre o sistema de justiça e o sistema de saúde", retirando a responsabilidade do programa de governo, das políticas públicas, e, principalmente, dos gestores públicos.

Demonstra visivelmente a falta de efetividade de uma análise legal e econômica das decisões tomadas na esfera Executiva, como exemplo, a decisão proferida em 16/08/2017 do Acórdão 1787/2017 do TCU, que reporta que os gastos "com processos judiciais referentes à saúde, em 2015, foram de R\$ 1 bilhão". Todavia, referida decisão não menciona que além dos gastos com o atendimento da medida judicial, estão os gastos com as custas processuais e, neste ponto, ressalta-se a importância do estabelecimento de padrões e procedimentos de análise econômica. 


\section{ANÁLISE ECONÔMICA}

A economia governa o mundo, esta é a realidade. Qualquer medida ou política pública tomada por determinado governo, afeta diretamente a economia. A economia fornece substrato para se viver. Essas observações não querem dizer que o pensamento econômico deve preponderar sobre o social; mas, fazer dela nossa aliada, na obtenção de melhores condições de vida para a sociedade. E do mesmo modo deve a Administração Pública atentar para tal ciência.

O matemático Pierre de Fermat desenvolveu um método matemático da "maximização e da minimização", e, segundo Amartya Sem, a consideração de tal critério matemático, revela-se primordial nas escolhas, podendo apontar para um caminho ponderado

O método é importante na matemática e na filosofia, mas também é largamente utilizado nas ciências, inclusive nas ciências sociais e, em particular, na economia..... processo de maximização na economia é visto principalmente como resultado de uma escolha consciente...o exercício da escolha racional...A disciplina da economia utiliza muito extensamente a abordagem da busca 'dos extremos' para prever as escolhas consideradas prováveis, incluindo a maximização da utilidade...a minimização dos custos[...] (SEN, 2011, p.207-208)

Bresser-Pereira leciona que "desenvolvimento econômico é o processo de sistemática acumulação de capital e de incorporação do progresso técnico ao trabalho e ao capital que leva ao aumento sustentado da produtividade ou da renda por habitante e, em consequência, dos salários e dos padrões de bem-estar de uma determinada sociedade" (BRESSER-PEREIRA, 2006, p.1). Manifestamente, seu entendimento, no texto referido, contempla a economia de um Estado como um todo; porém, o todo é formado por partes, portanto, se cada órgão do Poder Executivo, cada secretaria, cada agente público, cada gestor pensar no equilíbrio entre recursos escassos e necessidades ilimitadas, estarão promovendo o desenvolvimento integral do todo, fazendo o máximo com o disponível. 
Segundo o economista citado, "o desenvolvimento econômico implica mudanças na estrutura, na cultura e nas instituições da sociedade, de forma que é impossível analisá-lo apenas do ponto de vista econômico" (BRESSER-PEREIRA, 2006, p 4).

São as mudanças nas estruturas e na visão da Administração Pública que podem alcançar para o país, um maior e melhor desenvolvimento. Para tanto, há que se conjugar todas as ciências.

Todavia, parece que a Administração Pública não tem intenção de modificar seus paradigmas. Recentemente houve um encontro em Curitiba, entre médicos e magistrados, cujo tema do referido encontro era a judicialização da saúde e consequentemente a apresentação de ferramenta que auxilie os juízes em suas decisões, em diversas questões relacionadas à saúde. Os integrantes do Poder Judiciário não possuem conhecimento técnico e a ferramenta vem auxiliá-los em suas decisões. A ferramenta chama-se "NAT-Jus".

Claro, que todo auxílio que a Justiça receber é sempre bem-vindo. Por outro lado, sabe-se que o Poder Executivo tem como intenção a redução de custos; entretanto, não investe em seus agentes, bem como em termos estruturais da atividade administrativa, para que as decisões não precisem chegar ao Judiciário.

No portal do Conselho Nacional de Justiça, encontra-se a seguinte notícia do Secretário-executivo do Ministério da Saúde, Antônio Nardi

De acordo com Nardi, por ano os municípios, os estado e a União gastam cerca de $\mathrm{R} \$ 7$ bilhões para cumprir determinações judiciais. Entre 2010 e 2016, o aumento de ações foi de $1010 \%$. Até outubro deste ano a União destinou $R \$ 751$ milhões para o cumprimento de sentenças. Os estados que mais demandam judicialmente são Minas Gerais, Santa Catarina, Rio de Janeiro, São Paulo e Rio Grande do Sul. (CONSELHO NACIONAL DE JUSTIÇA, 12/12/2017)

Estima-se que o custo é bem maior e demandaria pesquisa exaustiva e demorada, que não é nosso objetivo por agora. O valor citado diz respeito, tão somente, ao cumprimento da decisão judicial, mas o custo do processo que recai sobre a União, Estados e Municípios. Assemelha-se mais, a tantas decisões paliativas. 
Por outro lado, a pesquisa efetuada pelo TCU, citada anteriormente, tem diretrizes mais objetivas, caminhando no sentido de mudanças efetivas no modo de agir da administração, permitindo que as ações sejam coordenadas. Em nosso sentir, tal maneira expressaria a forma com que a ciência econômica analisa os dados que tem a seu dispor e aplica da melhor forma possível.

Importante asseverar, que toda mudança depende de vontade política e de constante escrutínio dos cidadãos, como explicado por Czelusniak, em conjunto com outros estudiosos

No âmbito de Governos democráticos se impõe a existência de mecanismos de vigilância permanente e constante dos atos da administração, tendo em vista a necessidade de participação da sociedade como um todo nas decisões políticas. Assim, percebe-se que a avaliação de políticas públicas é um instrumento apto a fazer essa vigilância. Contudo, elementos indispensáveis à avaliação de políticas públicas são a transparência e a participação. Por meio desses princípios é que será possível a pressão social sobre as instituições governamentais para que as ações do governo se pautem no sentido de melhor distribuição das benesses aos seus cidadãos.(CZELUSNIAK, RIBEIRO, DERGINT, 2014, p.97)

A abertura para outras ciências somente engrandece, exemplo que se encontra na obra de Amartya Sen, que conjuga seu saber com a filosofia, provando o quanto se ganha com a imersão em outros campos. Amartya Sen não trata a economia como um deus, ao contrário, "[...] proclama, com urgência de um profeta, que as graves injustiças sociais do nosso tempo têm origem no trágico divórcio entre a ética e a economia [...] (CREDER, ARAÚJO, 2013, p.103)

Assim, de acordo com Amartya Sen, há que se conciliar Administração Pública e Ciência Econômica, com vistas a um novo momento, elencando ainda, que, no caso específico das decisões administrativas, além da legalidade deve se elevar em conta uma "análise arrazoada" cujo fundamento é a sua sustentação. 


\section{CONSIDERAÇÕES FINAIS}

Os objetivos da República são nobres e cabe a cada cidadão e a cada um dos Poderes cumpri-los. Tarefa que não é de fácil execução.

Contudo, a Administração Pública encontra-se no cerne da questão. Possui também, um aparato que the permite concretizar os ditames constitucionais e ainda, promover o desenvolvimento social, cultural e econômico do país e de sua sociedade.

Para tanto, observa-se que o apego aos gastos em procedimentos já não mais proporciona sustentação das finanças públicas.

A constante reavaliação é uma necessidade imperiosa, assim como a remodelação do sistema. Quando se fala em remodelação, não se quer tão somente o novo, mas, o melhor para a concretização de direitos fundamentais. A congregação entre órgãos, setores, gestores, Poderes tem que ser constante, objetiva e eficaz.

A ciência econômica traz novos meios e ferramentas, para que a Administração Pública, assentada na legalidade, possa atender com maior presteza e menor custo seus administrados.

A constante transparência e fiscalização de todo o aparato estatal é de vital importância para que as mudanças ocorram.

\section{REFERÊNCIAS}

BARROSO, Luís Roberto. A constitucionalização do direito e suas repercussões no âmbito administrativo. Disponível em https://www.editoraforum.com.br/wpcontent/uploads/2014 /09/A -constitucionalizacao_LuisRobertoBarroso.pdf. Acesso em 03/03/2018.

BRESSER-PEREIRA. O CONCEITO HISTÓRICO DE DESENVOLVIMENTO ECONÔMICO. Texto para Discussão EESP;FGV 157, dezembro 2006. Versão de 31 de maio de 2008. Disponível em 
http://www.bresserpereira.org.br/papers/2008/08.18.ConceitoHist\% C3\%B3ricoDesenvolvimento.31.5.pdf. Acesso em 01/03/2018.

CREDER. Fábio. ARAUJO Luiz Bernardo Leite. Ética, economia e justiça: a escolha social no pensamento de Sem e Smith. Dois pontos, Curitiba, São Carlos, vol.10, n.1, p.103-126, abril, 2013.

CZELUSNIAK, Vivian Amaro. RIBEIRO. Marcia Carla Pereira. DERGINT. Dario Eduardo Amaral. PARTICIPAÇÃO, TRANSPARÊNCIA E AVALIAÇÃO DE POLÍTICAS PÚBLICAS. Revista de Direitos Fundamentais e Democracia, Curitiba, v.15, n. 15, p.82-100, janeiro/junho de 2014.

DI PIETRO, Maria Sylvia Zanella. Direito Administrativo. 22. ed. São Paulo, 2008.

HOLANDA, Sérgio Buarque de. Raízes do Brasil. 24 ed., Rio de Janeiro: José Olympio, 1992.

MEIRELLES. Hely Lopes. DIREITO ADMINISTRATIVO BRASILEIRO.ed.33ㄹ. Malheiros Editores. São Paulo, 2006.

PEREIRA, Luiz Carlos Bresser. Reforma do Estado e Administração Pública Gerencial. 5.ed. Rio de Janeiro, FGV, 2003.

SCHIER, Adriana da Costa Ricardo. Serviço Público. Garantia fundamental e cláusula de proibição de retrocesso social. Curitiba: Íthala, 2016.

SCHIER, Paulo Ricardo. Presidencialismo de coalizão. Contexto, formação e cláusula de proibição de retrocesso social. Curitiba: Íthala, 2016.

SEN. Amartya. A ideia de justiça. Tradução Denise Bottmann, Ricardo Doninille Mendes. São Paulo: Companhia das Letras, 2011.

https://contas.tcu.gov.br/sagas/SvIVisualizarRelVotoAcRtf?codFiltro=SAGA S.Por que o serviço público não funciona....Vida Pública. Gazeta do Povo. 
http://www.cnj.jus.br.notícias;cnj;85915-ministerio-da-saude-alerta.

https://contas.tcu.gov.br/sagas/SvlVisualizarRelVotoAcRtf?codFiltro=SAGA

S.

http://portal.tcu.gov.br/imprensa/noticias/aumentam-os-gastos-publicoscom-judicializacao-da-saude.htm.

http://www.bresserpereira.org.br/papers/2006/06.7-

conceitohistoricodesenvolviment o.pdf.

Enviado: Setembro, 2019.

Aprovado: Setembro, 2019. 